\title{
From Counting Risk to Making Risk Count: Boundary-Work in Risk Management
}

\section{Citation}

Mikes, Anette. 2011. From Counting Risk to Making Risk Count: Boundary-Work in Risk Management. Accounting, Organizations and Society 36, no. 4-5: 226-245. doi:10.1016/ j.aos.2011.03.002.

\section{Permanent link}

http://nrs.harvard.edu/urn-3:HUL.InstRepos:41543203

\section{Terms of Use}

This article was downloaded from Harvard University's DASH repository, WARNING: This file should NOT have been available for downloading from Harvard University's DASH repository.

\section{Share Your Story}

The Harvard community has made this article openly available.

Please share how this access benefits you. Submit a story.

\section{Accessibility}




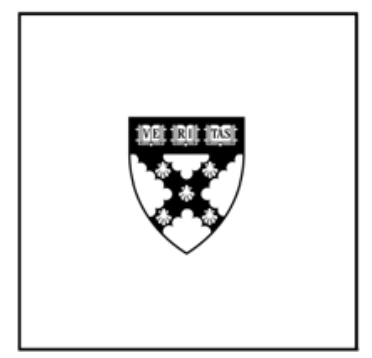

\title{
From Counting Risk to Making Risk Count: Boundary-Work in Risk Management
}

\author{
Anette Mikes
}

\section{Working Paper}

11-069 


\title{
FROM COUNTING RISK TO \\ MAKING RISK COUNT: \\ BOUNDARY-WORK IN RISK MANAGEMENT
}

\author{
Anette Mikes ${ }^{1}$ \\ Harvard Business School
}

For two decades, risk management has been gaining ground in banking. In light of the recent financial crisis, several commentators concluded that the continuing expansion of risk measurement is dysfunctional (Taleb, 2007; Power, 2009). This paper asks whether the expansion of measurement-based risk management in banking is as inevitable and as dangerous as Power and others speculate. Based on two detailed case studies and 53 additional interviews with risk-management staff at five other major banks over 2001-2010, this paper shows that relentless risk measurement is contingent on what I call the "calculative culture" (Mikes, 2009a). While the risk functions of some organizations have a culture of quantitative enthusiasm and are dedicated to risk measurement, others, with a culture of quantitative scepticism, take a different path, focusing instead on risk envisionment, aiming to provide top management with alternative future scenarios and with expert opinions on emerging risk issues. In order to explain the dynamics of these alternative plots, I show that risk experts engage in various kinds of boundary-work (Gieryn, 1983, 1999), sometimes to expand and sometimes to limit areas of activity, legitimacy, authority, and responsibility.

\footnotetext{
1 amikes@hbs.edu. I am grateful for the comments received from two anonymous reviewers and the Editor-in-Chief of Accounting, Organizations and Society, and the additional comments, support and inspiration I have received from Michel Anteby, John Elder, Harry Evans, Tim Fogarty, Robert Kaplan, Felix Kloman, Yuval Millo, Jan Mouritsen, David Newman, Michael Power and Robert Simons. I also thank workshop participants at the AAA Management Accounting Section (2009), Harvard Business School, North Carolina State University’s Enterprise Risk Management Initiative and Wharton Insurance and Risk Management Department.
} 


\section{FROM COUNTING RISK TO}

\section{MAKING RISK COUNT: BOUNDARY-WORK IN RISK MANAGEMENT}

\section{Introduction}

Risk management has been gaining ground in banking for the last two decades (Power, 2009; Mikes, 2009b), fuelled by regulators' and market participants’ long-held dream of taming uncertainty. This dream, in itself, is a manifestation of the "quantificational spirit" of our age, in which a "tyranny of numbers" (Boyle, 2001) brings uncertainty and complexity to heel. In particular, developments in financial economics have organized market uncertainty into recognizable categories of quantifiable risk (Bernstein, 1996; Millo and MacKenzie, 2009). But is this growth of risk management in banking inevitable? Is it dangerous? And is it really "risk management” that is steadily staking out new territory —or is it a variety of risk managements?

Paradoxically, the growth of risk management is often stimulated by what appear to be its failures. The two-decade history of modern risk management in banking has been punctuated by corporate failures (Barings Bank), large-scale one-off losses (often associated with fraud, such as those suffered by Allied Irish Bank in 2002 and Société Générale in 2008), relatively localized systemic crises (such as the Asian bank crisis of 1996 and the Russian bond crisis of 1998), and, last but not least, a systemic financial crisis on a scale never seen before. Each of these events was cast as a risk-management failure, yet the ideal of risk management has survived. The financial crisis of 2007-2009 led regulators and industry observers to call for firms to have executives exclusively devoted to enterprise-wide risk oversight, particularly since it emerged that one of the victims of the subprime credit debacle, Citigroup, had ineffective risk oversight and another, Merrill Lynch, had no chief risk officer (CRO) at all (Dobs, 2008). Many argue that the chief risk officer’s role in corporate governance is going to grow. As National City’s CEO, Peter Raskind, argued in a 2008 issue of The American Banker: “This environment has absolutely underscored the need for that person. But it's not just credit risk. It's operational risk, reputation risk, and so on. Nobody wants another 2007” (Dobs, 2008).

In response to the proliferation of the measurement imperative in economic life, Power (2004a) proposes an explanatory framework which postulates that the evolution of performance 
management is a cyclical recursive process of “counting, control, and calculation,” punctuated by innovation, crisis, and revision. These two sequences are intertwined: Controlling experts develop methods of counting (each of which is an innovation) and use them for control until there is a crisis, which forces them either to (re)calculate in order to intensify their control or else to subject their counting methods to revision or reform.

What makes Power's "metrological dramas" cyclical is that, in the face of crisis and criticism, proponents of “counting” do not abandon their measurement efforts but, rather, intensify them (Power, 2004a), something which made Power himself uneasy. Having modelled organizations' relentless drive to expand performance measurement into hitherto uncontrolled areas, he began to warn against the consequences of that expansion (Power, 2004a, 2004b, 2009). He argues that, as risk management continues to evolve through cycles of innovation in measurement, crisis, and revision, it pushes metrics into more and more areas which are properly the domain of human judgment, with results that are "at best ambivalent and at worst dysfunctional” (Power, 2004a:771). In light of the recent financial crisis, Power concluded that the risk management of everything turned out to be the risk management of nothing (Power, 2009; see also Taleb, 2007).

While Power's framework of “counting, control, and calculation” and his expectation that pushing risk-management practices ever further is likely to be dysfunctional have provoked much thought and discussion, both still await empirical scrutiny. This paper is a first attempt to apply his framework in the field.

Based on two detailed case studies (first reported in Mikes, 2009a) and 53 additional interviews with risk-management staff at five major banks over 2002-2010, I show that Power's cycle is contingent on what I call the “calculative culture.” Controllers who display "quantitative enthusiasm” would do what Power's model suggests, but there is another control style which takes a very different path. One of my in-depth field studies fitted Power's cyclical conception. In this organization (referred to as Fraser Bank), risk metrics gradually colonized hitherto uncontrolled areas of uncertainty, even in the face of recurring internal organizational crises when risk methodologies came under scrutiny from external and internal constituencies. The other field study (in an organization referred to as Goethebank), however, suggested an alternative style of risk management which resists the urge to push metrics into carefully protected areas of judgment. In 
this style of risk management, the emphasis is on using "softer" instrumentation" to frame and visualize non-measurable uncertainties.

To understand how some organizations displaying a particular calculative culture come to be so committed to risk measurement while others with a different calculative culture do not, I draw on sociological studies of expertise to argue that risk experts engage in boundary-work (Gieryn, 1983). That is, for a variety of reasons, experts try to define what is and is not their remit, often with respect to competing or complementary fields of expertise. My field studies suggest that the boundary-work of risk experts furthers two different approaches to risk management, depending on the calculative cultures they display. Some risk controllers who adopt quantitative enthusiasm expand first-order measurements (initial risk quantification) into new domains of risk, and use these measurements to create second-order measurements (risk aggregation), which not only demarcate an aspect of performance (risk-adjusted performance) but also signify a distinct expertise which entitles the controller to a degree of organizational control. Other risk experts (displaying quantitative scepticism) combine initial risk measurements with “envisionment” practices based on the controller's experience and intuition, and expand "softer" instrumentation into the domain of non-measurable strategic uncertainties. By limiting risk quantification to first-order measurement ${ }^{2}$, controllers in this group lack the analytical mystique wielded by those in the first group and they appear to have deliberately left the boundaries between themselves and the rest of the organization blurred and porous in order to influence decision makers in the business lines. But what might be a hindrance to creating a distinct expert group-one kind of boundary-work-can be a help in crossing organizational boundaries in order to "get things done" in the business lines — another kind of boundary-work. While the first approach appears to be more effective in creating an independent and distinct expert function, its practitioners seem to have limited relevance to (or lack the ambition to participate in) the discussion of non-measurable strategic uncertainties.

\footnotetext{
${ }^{1}$ Power himself left open the possibility for another unspecified, unevidenced route when he wrote: "Emerging agendas in the field of risk management are a case in point, where dreams about measuring the future co-exist with demands for greater communication of the importance of 'softer' instruments with more qualitative calibration" (Power, 2004a). However, he later concluded that this was not happening in risk management (Power 2007, 2009). ${ }^{2}$ Power distinguishes between first-order and second-order measurements (Power, 2004a:771). First-order measurement relates to the controllers' attempt at classification that makes counting possible, the "translation" of the phenomenon into measurable quanta, and the creation of legitimate instrumentation, all of which requires protracted political work. Second-order measurement refers to controllers' efforts to aggregate first-order numbers and to create ratios and indices. These further "measures of measures" have a life of their own as they become integral to performance measurement systems (e.g. by the calculation of profitability), compensation and insurance systems, and so on.
} 
This paper is organized as follows: The first section introduces risk management and outlines four major themes that guide its technical development: first-order measurement, secondorder measurement (or risk aggregation), control (risk-based performance measurement), and remedial calculations. The second section introduces the notion of boundary-work in order to focus and structure my analysis of the field cases. In the next sections, I apply this framework to the cases of Fraser Bank and Goethebank and show how the five additional cases shed further light on the characteristics and conditions of possibility for the alternative pattern of risk management-risk envisionment. The final section concludes and outlines further avenues for research.

\section{From counting risks to controlling uncertainty}

In the metrological drama of risk management in banking, as in other cycles of performance-measurement innovation, the first act is counting, which itself has two steps. The first step is first-order measurement - the creation of categories that contain measurable quanta and the protracted work of creating measuring instruments (calculative technologies). Indeed, the starting point for all common risk-management frameworks is the classification of uncertainties into categories such as market risks, credit risks, and operational risks (Mikes, 2009a). ${ }^{3}$

The next step in counting risk is second-order measurement-the aggregation of numbers into units of control and the derivation of ratios and indices that can serve as the backbone of performance measurement. When international regulatory changes in the early 2000s required banks to determine adequate capital levels in relation to their aggregate risk profiles, the concern for risk quantification was joined by a concern for risk aggregation: “Common tasks for dedicated risk management functions include the development ... of common definitions and metrics for risk throughout the firm.... The Working Group believes that supervisors and regulators should continue to monitor and support ... firms' efforts to develop means of aggregating (to the degree possible) their risks” (Basel Committee on Banking Supervision, 2003: 1-2). Aggregating risk

\footnotetext{
${ }^{3}$ The following commonly quoted definitions apply to the main risk categories (Drzik et al., 2004): Market risk arises from changes in the value of financial assets and liabilities (i.e., trading book) due to volatility in market prices (interest rates, currencies, equities, commodities). Credit risk arises from changes in the value of assets (i.e., banking book) and off-balancesheet exposures due to volatility in default rates or credit qualities. Bancassurance firms and insurers add the additional category of insurance risk, which arises from the volatility of insurance claims around the expected level of claims. Operational risk has long been defined in banking as a residual category capturing all of the risks not covered in the first three categories. Accordingly, the regulatory definition settled upon by the Basel Committee is very general: the risk of loss resulting from inadequate or failed internal processes, people, and systems or from external events.
} 
exposures had been a challenge to risk practitioners for a long time, largely because there were many varieties of risk measurement being applied to many types of risk but little understanding of the interrelationships between those various risks. ${ }^{4}$ The recent development of the economic capital metric as a common denominator measure for market, credit, and operational risks has enabled firms to aggregate their quantifiable risks into a total risk estimate (Mikes, 2009a). ${ }^{5}$ Economic capital can be used to represent risk aggregations at levels from product line to business unit to the entire organization.

These two levels of counting — risk quantification and risk aggregation — set the stage for the second part of Power's cycle: control. Risk-based performance measurement rendered a growing slice of organizational life susceptible to managerial control and regulatory monitoring.

It would seem, though, that there were still fault lines in the system; the two-decade history of modern risk management has been punctuated by crises and failures. Yet time and again, new or reformed metrics appeared and gained legitimacy as remedies. According to Power (2004a), this third part of the cycle, remedial calculation, is responsible for the continuous development of performance measurements (and risk management) and their expansion to new areas of control. The technical developments of risk regulation reflect this. Early capital regimes required banks to measure only their credit risk and to set aside capital buffers to absorb credit losses. In 1996, international bank regulators required banks to measure their market risk as well and set aside capital against it. The next stage of regulatory reform not only called for more accurate credit-risk measures but also required banks to extend their measurement (and capital adequacy) frameworks into a hitherto "uncounted" area—-the realm of operational risks.

In order to further understand how risk-management practices progress from counting risk to making risk count in decision making and action, we need to move inside organizations.

In a field study carried out at two banks (Mikes, 2009a) I described the apparent coexistence of alternative models of risk control. In particular, I postulated two types of risk

\footnotetext{
${ }^{4}$ In any large portfolio, diversification benefits, concentration penalties, and correlations may exist between various risk exposures.

${ }^{5}$ Economic capital, like value-at-risk (VaR), is based on a loss distribution and estimates the maximum likely loss. While VaR is a terminology used in the context of market risks, economic capital is a general term, used to describe the maximum likely loss in any risk category (credit risk, operational risk, or market risks), given a standardized set of parameters (e.g., the economic capital at 99\% probability on a one-year horizon expresses the maximum likely loss that would occur over the next year and would only be exceeded by an even larger loss with a small probability of 1\%). Consequently, economic capital is applied as the statistically estimated amount of capital that could be used to cover all liabilities in a worst-case scenario, whether that be a plunge in the market or an explosion in a data centre.
} 
management: one driven by a strong shareholder value imperative (risk management by the numbers), the other corresponding to the demands of the risk-based internal control imperative (holistic risk management). The study explained the differences in the two risk management styles by describing alternative calculative cultures, which in these cases shaped managerial predilections towards risk management practices. However, explicating the dynamics through which calculative cultures may bring about different risk-control styles needs further research into the day-to-day realities of risk management.

\section{Inside the metrological drama of risk management: Boundary-work}

Risk management, being a highly “technologized” activity (Beunza and Stark, 2004), can reasonably be expected to assume an organizational significance similar to that of other fields of recognized expertise (MacKenzie, 2005) and other calculative practices of financial reckoning (Hopwood, 1983, 1987; Swieringa and Weick, 1987; Hopwood and Miller, 1994). In particular, risk practitioners claim the ability to familiarize decision makers with enterprise-threatening risks that have previously been recognized only intuitively (such as the multiple risks of lending large sums to large, global organizations) or not at all (such as the emerging category of operational risk; Power, 2005). However, the ability of risk practitioners to influence organizational activities depends not only on the validity of their technologies, but also on their ability to make those technologies appear indisputable and indispensable, a process known as "black-boxing” (Callon and Latour, 1981; MacKenzie, 2005). More generally, advocates of particular practices of performance measurement need to make even controversial counting systems seem natural and unavoidable in order to incorporate them in the monitoring and control of organizations.

It appears, then, that the "metrological drama" of risk management-a dynamic process “acted out by accountants, actuaries, economists, consultants and many varieties of financial and non-financial analysts, fuelling demands for the measurement of everything” (Power, 2004a:767)— is not simply a relentless struggle to count and calculate risks, but rather a series of rhetorical claims, some made in the face of outright challenge and some in the normal course of organizational life. Largely through these rhetorical claims and the protracted political and technical work that accompanies them, risk-management experts establish their "cultural cartography" (Gieryn, 1999) — the contours and boundaries of their field. 
In examining the demarcation of risk management from other control activities as a practical problem for risk managers, I draw on Gieryn’s studies of “boundary-work” (Gieryn, 1983, 1999). Gieryn coined the term "boundary-work" to describe the discursive practices by which scientists attempt to attribute selected qualities to themselves, scientific methods and scientific claims in order to draw a boundary between science and non-science (Gieryn, 1983: 782). Drawing on Geertz's (1973) synthesis of two initially separate approaches to ideologies, Parsons’s (1967) "strain theory" (suggesting that ideologies are created to smooth inconsistencies that the ideologist experiences in the face of conflicting demands), and Mannheim's (1936) interest theory (namely, that ideologies serve to advance the interests of the ideologist), Gieryn (1983) found that nineteenth-century English scientists had promoted a variety of ideological arguments to justify their request for greater public support and to demarcate science from religion and engineering, both of which had more authority and prestige at the time. He distinguished three genres of boundary-work: expulsion, expansion and the protection of autonomy (Gieryn, 1999: 15-17).

Expulsion defines the contest between rival authorities, each of whom claims to be scientific. As scientists seek to legitimate their claims about "real science", they demarcate it from several categories of posers: pseudoscience, bad science, popular science, and so on. For example, in the so-called "prayer gauge" debate in 1872, the Victorian physicist John Tyndall demarcated science from religion by emphasizing its practical utility, empirical nature and scepticism (while deeming religion as practically irrelevant, metaphysical and dogmatic). He drew a further contrast between science and mechanics (engineering) by declaring science as the fount of technology and technical progress and emphasizing its theoretical nature, as opposed to the commonplace observations of "practical men". Gieryn argues that as the borders get policed, scientists learn where they may not roam without transgressing the boundaries of legitimacy and limit themselves to, and maintain monopoly over, preferred norms of conduct. Expansion takes place when those speaking for science seek to extend its frontiers. Finally, boundary-work is mobilized in the form of protecting professional autonomy against outside powers (legislators, corporate managers) that endeavour to exploit the authority of science for their own purposes. In particular, scientists will draw boundaries between what they do and consequences far downstream in order to escape responsibility and blame, which often come coupled with intrusive demands for accountability. That boundary-work is an immensely useful concept to illuminate the social organization of 
scientific knowledge is demonstrated by its successful applications in a wide range of case studies (for a review see Lamont \& Molnar, 2002).

Like scientists, professionals have also wanted to distinguish themselves from amateurs and charlatans by erecting the boundaries of their profession against outsiders (Sarfatti-Larson, 1979). Indeed, the notion of "professions" originally emerged as a demarcation problem, i.e. a problem of boundaries between "special” and ordinary occupations (Lamont \& Molnar, 2002:177). Abbott (1988) argued that professions compete not only with outsiders, but with one another as well, for jurisdictional monopolies and for the legitimacy of their claimed expertise. This competition usually assumes the form of disputes over jurisdictional boundaries.

While Abbott emphasizes the objective character of the tasks that group X claims to have professional monopoly over, Gieryn and others who have used the notion of boundary-work emphasize its rhetorical, discursive nature: how does group $\mathrm{X}$ define itself through descriptions of how they are not like groups $\mathrm{Y}$ and $\mathrm{Z}$ ? It is in this context that that boundary-work can become an important resource for aspiring professionals in establishing authority. Risk managers, like many other occupational groups, particularly those wishing to be seen as "professions" therefore can be expected to engage in ideological rhetoric and boundary-work, in order to stake claims over particular kinds of work.

Further, Abbott maintains that professions such as medicine and accounting are made, not by licensure or ethics codes, but by their ability to create an abstract body of knowledge. "Any occupation can obtain licensure (e.g., beauticians) or develop an ethics code (e.g., real estate). But only a knowledge system governed by abstractions can redefine its problems and tasks, defend them from interlopers, and seize new problems-as medicine has recently seized alcoholism, mental illness, hyperactivity in children, obesity, and numerous other things” (Abbott, 1988:8-9).

Risk management at banks has often been described as a highly abstract, analytical activity that draws heavily on advances in statistics and financial economics (Bessis, 1998; Marrison, 2002; Field, 2003). There are now institutions that certify this body of knowledge; for example the New York-based Global Association of Risk Professionals set out to codify and certify financial riskmanagement knowledge in 1998. However, the existence of several other professional bodies in the global risk-management arena (such as the Professional Risk Managers International Association, also based in New York, and the Institute of Risk Management, headquartered in London) suggest that the professionalization of this field is at an early stage, with competing institutions making 
knowledge claims on a diverse array of risk concerns. Much of risk management is in fact carried out within banks by the use of proprietary models, such as those deployed at Wellfleet Bank (pseudonym) and J.P. Morgan Private Bank (Mikes, 2008 and Mikes et al., 2010, respectively). The specification of internally developed risk models (with the notable exception of Value-at-Risk) rarely enters the public domain or the curricula of the professional bodies just mentioned. It is therefore at the microsociological level that the early professional struggles of risk managers play out. Influenced by regulatory guidelines and a slowly emerging consensus concerning certain risk practices, career risk managers and CROs move from organization to organization, mobilizing various concepts, frameworks, technologies, risk models, interpretations, and prior occupational experiences in order to describe, measure, and extend control into new areas of uncertainty.

Given the state of the risk-management field, the rhetoric that CROs deploy in demarcating risk management inside organizations is important. It can be expected to be shaped by their personal views of the applicability and relevance of the abstract tools, models and practices of risk management in various domains of risk, decision-making and control. Therefore boundary-work can be seen as an important link between the calculative cultures displayed by senior risk officers, and the nature of risk control they ultimately bring about.

Gieryn deemed science a "cultural space” (1999: 10), mapped by its practitioners' boundary work, i.e. spatial segregations and their rhetorical claims. I find that risk management has its own cultural cartographers. Some draw the boundaries of risk management to encompass only "measurable" risks, others make claims on the control of uncertainties for which reliable measurements do not exist and may never be found. Risk practitioners skilfully apply scale both to "zoom in" on differentiations within risk management and to provide an aerial view of risk management's place on the map of organizational expertise.

\section{Observing risk management in action: Method}

Between January 2001 and September 2005, I undertook an in-depth study of the riskmanagement practices at two large banks referred to here as Fraser Bank and Goethebank. The banks were similar in balance-sheet size and in scope-retail, corporate, and wealth-management 
services-but only Fraser Bank had a sizable, well-integrated investment bank. ${ }^{6}$ Each had a reputation for leading-edge risk management and both had developed risk management under the “response imperative” (Power, 2007:5); Fraser Bank turned to modern risk-management techniques after a significant loss — the first in its 300-year history-during the early 1990s UK credit crisis and Goethebank Group appointed a CRO after embarrassing losses in the 1998 Russian bond crisis.

While Fraser Bank was an ardent advocate of risk-adjusted performance measurement, Goethebank was not. Comparing such a "matched pair” of cases (Ahrens and Dent, 1998) helps the researcher to move systematically from field material through interpretation to explanation (Bruns and Kaplan, 1987; Ahrens, 1996).

I conducted 75 in-depth interviews with senior finance, lending, strategy, managementaccounting, and risk-management staff at the two banks. I was also able to observe risk management in action in both banks. Goethebank provided me with an office in the central riskmanagement department, so I could observe staff at work and participate in informal meetings, get-togethers, and chats. Fraser Bank invited me to an internal risk-policy workshop, and then gave me wide access to investigate the evolution of its risk management. Within the boundaries of confidentiality, both banks provided source documents such as internal reports, presentations, and annual reports.

Between June 2006 and June 2010, I conducted 53 in-depth interviews at five other financial institutions (referred to as Banks A, B, C, D, and E), not only to be sure my observations were generalizable and not idiosyncratic, but also to see how processes and outcomes were qualified by local conditions and thus to develop more sophisticated descriptions and more powerful explanations.

I conducted semi-structured interviews to understand the organizational roles of senior risk officers. Interviewees could reflect on any experience relevant to understanding their "philosophies," as some of them referred to the ideologies they had developed to persuade others of the relevance of risk control and to resolve the conflicts they felt in exercising it. I met regularly with senior risk officers during the four-year period in order to follow the developments at each site from their perspectives.

\footnotetext{
${ }^{6}$ Goethebank Group had acquired a U.S. investment bank shortly before this study started, but throughout my fieldwork, the investment bank was run as a separate entity. My research focuses on the non-investment-banking arm of Goethebank Group, which I refer to as "Goethebank.”
} 
My cross-case analysis (Miles and Huberman, 1994) follows Yin's (1984) replication strategy: A theoretical framework is used to study two initial contrasting cases in depth, then further cases are examined to see whether the patterns and contrasts found match those in the initial cases. This approach allows the researcher to form types or families (Miles and Huberman, 1994) from quite complex configurations. In this paper, I sort the cases into two clusters on the basis of the remit, ideologies, and modus operandi of senior risk officers and their use of riskmeasurement technologies. This clustering is the result of systematic comparisons and contrasts drawn between the cases and of the patterning of the data by categories such as contextual factors (e.g., type of business), risk activities, decision-making incidents, the strategic planning process, the structure of the risk organization, the professional backgrounds of senior risk officers, and their risk-management ideologies (as in Gieryn, 1983).

\section{Risk control via measurement}

This section summarizes the cases of Fraser Bank and three other banks (A, B, and C) that made risk measurement the focus of risk management.

\subsection{Counting, control, and calculation at Fraser Bank}

Fraser Bank "organized” risk into three silos—market risk, credit risk, and operational risk (the latter also referred to as "non-financial and compliance risk"-each a distinctive community of practice with a highly specialized language (Beunza and Stark, 2004). The central risk function developed quantified, model-based risk-measurement methodologies. In keeping with the calculative idealism at Fraser, senior risk officers judged the progress of their function by how much of the bank's risk was covered by such methodologies. As the risk-policy director recollected:

Initially, there was a market-risk-management team and a credit-risk-management team. But even the market-risk-management team was not very professional. We did not have a proper measurement system. We did have crude measurement systems.... Market risk was managed by the treasurer. The head of credit-well, his job was regarded as taking big lending decisions. Operational risk at that stage wasn't really talked about. Risk management, as we now know it, has been evolving since 1993. First we made the management of market risk more professional, so it is much more structured and quantified. Then we made credit risk more quantified. The job of the 
Chief Credit Officer became quite different. Even though he was still quite involved in big decisions, his job was to manage the portfolio rather than individual credits.

We can see in this account the protracted boundary-work that senior risk officers at Fraser undertook: They applied a rhetoric that privileged "proper measurement systems" (risk measurement) over previous, potentially competing representations of risk (i.e., the judgment, based on experience, which the treasurer or the head of credit used to apply). They advocated a "more quantified” approach to risk assessment as "more professional."

After the risk-management function adopted value-at-risk, its cultural cartographers were able to draw all forms of financial risk except asset-liability management (interest-rate risk) away from the treasury function, dismissing treasury's old methodology as "less professional.” Credit management, traditionally a stand-alone staff department, also became part of the evolving riskmanagement function and the remit of the chief credit officer expanded from a concern with large individual credit exposures to oversight over the portfolio of all loans, on the grounds that risk quantifications now enabled the risk function to aggregate individual risk exposures. For each major lending area (credit cards, mortgages, commercial lending, and so on), Fraser implemented quantitative credit measures, based on statistical estimates of the likelihood of credit defaults and the expected losses. These were then aggregated to an overall credit loss distribution and an economic capital estimate indicating the maximum likely loss in the credit portfolio. There was a separate body in the bank's management committee structure devoted to discussing and updating the methodologies in use.

Through years of risk calculation, risk came to be seen as controllable. At the same time, the risk function's claim over that controllability was embodied in a rule (in effect, an ideology), shown in Figure 1, that risks with a high degree both of measurability and of liquidity ${ }^{7}$-namely, market and credit risks - were well under control while risks that were low on both dimensions—namely, strategic and legal risks-were uncontrollable. Operational risk was somewhere in between. When my study began, the operational-risk team was experimenting with methodologies for quantitative assessment. Many risks assumed to be "non-financial" (hence non-measurable) at the time of my interview with the risk-policy director (2003) turned out to be quantifiable under the relentless drive of Fraser’s "quantifying spirit."

\footnotetext{
${ }^{7}$ That is, whether or not there was an external market that allowed banks to price and trade/hedge/insure the risk.
} 
By meticulous loss-data collection, simulations, and the subsequent discoveries of the nature and the loss distributions of hitherto unmeasured risks, Fraser's risk officers extended the boundaries of risk quantification well beyond the original financial-risk mandate. First-order risk measurements were aggregated into a common second-order risk metric (economic capital), initially for the credit-risk portfolios but later for other risk types such as operational risk (tax risk, IT risk) and credit risk (mortgages, credit cards). Economic capital, aggregated across risk types within a business unit, was the basis for risk-adjusted performance measurement. As the director of risk analytics in 2007 explained:

[W]e have a fully quantitative model. We have a loss distribution for every single approach and risk held by each business area, which then join together to give us a group loss distribution. We do it for each risk category, even operational risk: tax risk, IT risk...We measure operational risk at the group level and then sub-divide that into each business unit. So we know how much economic capital to allocate to each business. All compensation is on a risk-adjusted basis. The compensation schemes are based on a scorecard, but first and foremost on economic profit growth.

But the transition from counting to control—from "counting risk" to "making risk count"was not accomplished without challenge. Risk-quantification technologies are malleable and open to challenge and criticism. In the mid-1990s, Fraser's continuing business growth required continuing total economic capital growth. But an increasing amount of economic capital was left unallocated at the centre. The economic capital team felt that some business units took on more risk than was reflected by the historical trends of their risk profiles, which was not yet reflected in the risk-measurement methodology. Initially, the team considered this a mere technical problem and proposed a change to the allocation methodology. However, the fastest-growing business unit, which generated the largest segmental profit in the group, claimed that the capital allocations suggested for it by the new model were unacceptably high. A two-year credibility contest ensued, which focused not only on risk analytics but also on the motives and qualifications of the contestants (Gieryn, 1999). The business unit's experts used the uniqueness of the economic capital teams' method to undermine its credibility, while also claiming that the head of the economic capital team was fighting a personal "vendetta” against the business unit. The head of the economic capital team, who had based his team's methodology on advances in financial economics and had 
advocated it at industry conferences as "innovative" and "leading edge," was incredulous that these claims were not prevailing inside his own organization. Eventually, he and his team left the bank. But the capital-allocation anomalies remained ${ }^{8}$ and senior planners were worried:

We feared at some point the market was going to turn around and say to us: "You are not allocating out [xx bn] of capital to business lines. That's really odd. Why is that?” That's what we thought the worst scenario is going to be. ${ }^{9}$

A group risk director was appointed to oversee all risk-measurement activities; he appointed a new head of economic capital, a Ph.D. in physics who had worked in the very same large business unit that had defeated his predecessor. He called for a senior cross-functional steering groupincluding representatives of the most powerful business units as well as the group risk director and the group finance director-to guide the economic capital project. The project arrived at a new allocation approach which resembled the "industry average" in terms of its methodological sophistication ${ }^{10}$ and did not suggest radical changes in capital allocation for any particular division. Nevertheless, it solved the anomalies of the previous method by increasing capital allocations across the board. It was signed off in November 2002 with unanimous support.

Thus, the allocation of risk capital turned out to be as much a political process as other forms of budgeting were (Bower, 1970). Risk calculation had entered the realms of organizational control where it could and did generate organizational criticism and resistance; protracted political work was therefore required to hold that ground. At this level, risk numbers - however valid — did not necessarily work by themselves, but they could be made work.

One of the requirements was boundary-work. While the fast-growing business unit won its first battle with the risk function, that did not change the cartography of internal capital control. The reorganized and more politically savvy risk function may not have allocated as much economic capital to the fast-growing business unit as it would have liked to, but its boundary-work was successful. Not only did these risk managers render their claim over economic capital allocations real enough for others to act on, but they also enjoyed cascading influence through their design of the new (compromise) performance measurement and reward system which privileged economic profit.

\footnotetext{
8 The 2002 annual report showed that $8 \%$ of the bank's average economic capital was held at the group centre, unallocated to business units. Another analysis, showing the allocation of average economic capital to risk types, showed the same thing.

${ }^{9}$ Assistant Director, Group Strategy and Planning, Fraser Bank

${ }^{10}$ Assistant Director, Group Strategy and Planning, Fraser Bank
} 


\subsection{Risk measurement and boundary work}

Between 2006-2010, I studied three other banks whose senior risk officers placed risk measurement at the centre of risk management and engaged in several types of boundary-work. Risk experts expanded their remits, put up interpretative walls to protect their professional autonomy (Gieryn, 1999), and drew boundaries between what they did and the consequences downstream. The final case (Bank C) also shows how the risk-management function's cultural cartographers drew and redrew boundaries according to their ambitions and circumstances.

\section{Bank A}

Bank A was a UK bank, focussed on retail and commercial banking. Prior to the credit crisis, Bank A's CRO (who reported to the finance director), convinced that the risks he needed to care about were both individually and collectively measurable, had been quantifying and aggregating risks in order to link economic capital calculations to performance measurement.

What we do is push as much of the decision making as possible to automated, quantitative rules. However, we have to apply judgmental considerations as to whether it's appropriate for that particular decision to be made on quantitative grounds, so it needs a kind of qualitative overlay and check whether applying quantitative rules makes sense. But generally, we try to apply as many quantitative rules as possible.

This risk function's "measurement dreams"-its ambitions to expand risk measurementwere based on an assessment of "appropriateness.” Like Fraser Bank's senior risk officers, Bank A's CRO made a deliberate decision about which risks were controllable. His criterion for including a product type into his map of measurable and controllable risks was "homogeneity." He considered Bank A's loan portfolios (such as mortgages and small and medium-sized enterprises in the UK) homogeneous enough to have assessable statistical properties, such as loan-loss distributions and expected loss. It was understood that the reliability of the expected-loss trends over time was conditional on there being no change in the underlying loss-probability distributions. Risks that could not be gauged from the recent history of homogeneous product types were not included in the risk function's cartography. In his discussions with the board, the CRO stuck to the recent trends in risk measurement, product by product:

I do a very high-level monthly board risk report and there's a sub-committee of the board, the risk committee, where we give them much more detailed information. The sort of things we describe [to the board] are issues like why expected loss has gone up in the commercial bank. 
Now I might note that the expected loss in the commercial bank was $x$ basis points three months ago and it's $y$ basis points now. The reason for the change might be a particular change in the mix of lending or rating downgrades in the portfolio. The risk committee, which is a subcommittee of the board, will get a detailed analysis of that. Then the board makes the strategic calls. I think risk management kind of influences that, risk measures influence that, models influence that. But at the end of the day, decisions boil down to what the board thinks is the right strategy for the institution.

Bank A's CRO did not feel it was part of his remit to discuss scenarios with the board that presumed major changes in the environment; that was the responsibility of the CEO and the board.

\section{Bank B}

Bank B was the investment-banking arm of a global financial services group, but it had developed its own risk-management framework. The director responsible for risk-management methodologies and processes (henceforth "director of risk methodologies") echoed the general conviction among Bank B's senior risk officers that risk aggregation (second-order risk measurement) was key to managing the business:

Having a robust, thoughtful, well-grounded measurement approach across your financial risks is the bedrock on which you want your risk processes to stand. In a big, complex organization [such as ours], getting an aggregate view of risks is important. The other important thing about measuring is comparison between businesses. That's where economic capital is very powerful. Our comprehensive framework for measuring risk is an economic capital one. Economic capital includes market and credit risks in it. To us, it really is the common measure of risk. We aggregate it across businesses. I would view EC as the overall risk appetite measure: Every year, the board has to sign off on the overall economic capital limits for the divisions.

The director of risk methodologies displayed the bank's quantitative enthusiasm for risk modelling:

These mechanisms [risk models] don't manage the risk for you. What they do is they give you the starting point, that when you are going to make risk-management decisions, you're doing it based on good quality information and ... correct information. I'd be as blunt as that, because I think if you can't capture all risks pretty comprehensively and measure them consistently, then no matter how skilled or experienced your people are, there's going to be a limit on how good they can make 
their decisions, because they're not looking at the true picture. They're either looking at more risk than you've really got, or less risk than you've really got.

Like Fraser Bank, but unlike Bank A, Bank B completed and black-boxed its riskaggregation methodologies, so that economic capital limits for the business lines allowed the board to set annual targets (monitored quarterly) as levers of diagnostic control (Simons, 1991). In all three banks, though, the boundary-work was expansionist. Senior risk officers enlarged the quantifiable risk universe in the name of completeness and consistency.

While Bank B's CRO reported directly to the CEO, his influence was confined to the discussion of quantified-risk trends and capital-management issues. He was one of three executives setting the monthly rolling agenda of the Capital and Risk Management Committee, whose discussions were carefully demarcated from other board-level concerns:

This is not a platform for strategy discussions; those take place at the executive board level. I don't come in saying, "Which company do we buy today? Which asset do we sell today?” That's a separate thing for the strategic-planning function.

Boundary-work was an effective mechanism for not only deflecting but also displacing blame for the financial losses that, by 2009, were seen-in the media and in the public consciousness - as failures of risk management (and, in particular, of risk modelling; see Taleb, 2007). Banks A and B suffered significant financial losses in the credit crisis, but their senior risk officers had demarcated a boundary between risk measurements and strategic decision making and could now point to this boundary to deflect criticism that might have questioned the legitimacy of their expertise. Bank B’s director of risk methodologies reflected:

The essence of avoiding a bad thing is you have to take action before you know it's bad. You have to take action when you're still in a state of uncertainty and the action is going to cost you money. I'm a reasonably experienced risk person, but I'm not, I'm not the person who made those calls. I'm not the person who even suggested they [the board] make those calls, you know, because it's not my job.

Bank B's senior risk officers blamed neither risk models per se nor any individual; instead, they talked about a wider responsibility dissipated across a large, complex organization. As the director of risk methodologies put it: 
It wasn't a failure of models, it's just failure of creativity. Our risk assessment wouldn't anticipate the catastrophic circumstances. Then [under those extreme circumstances] our portfolios performed particularly badly and the diversification [benefit] was not as much as we thought. You know-people went-we weren't imaginative enough around what could go wrong and there wasn't the culture to be able to consider the unlikely. Nobody said, you know, it would be terrible if that happened, however I'm positively choosing not to reduce the risk because I think it's so unlikely that I don't want to spend that money.

In both banks, boundary-work was tailored to circumstances. Their cartographies were more expansionist when the economy was stable and they could enlist notions of homogeneity, completeness, and consistency. During the financial crisis, they sought to draw boundaries between their work and the dire effects of strategic decisions made by others. In both banks, senior risk officers had strong convictions about which risk issues were properly within their remits; the criteria being homogeneity for Bank A's CRO and the availability of high-quality information for Bank B's. The next case shows how flexibly senior risk officers can interpret such criteria; risk management becomes whatever best distinguishes it from other expert realms exerting organizational control.

\section{Bank C}

Bank C was a combination of a large retail bank and an investment bank. The latter focused on corporate lending and asset management and, with its significant proprietary trading business, was seen as an active risk-taker among financial services firms. For the CRO, risk measurement was the key to risk management, but he recalled that his early system-building had been particularly challenging:

I had to build an entirely new organization from scratch. We designed a dedicated credit process; hired and trained credit staff, as there were no credit people with derivatives know-how in the market; built credit-risk engines with the help of traders; and created our own Potential Future Exposure model, using Monte Carlo simulations and stress-testing portfolios. After that, we had to build a credit system that could integrate all these functions and aggregate our derivative counterparty exposure globally. These were six very challenging years.

Bank C's CRO, like those of Fraser and Bank B, invested heavily in second-order risk measurement (risk aggregation) as well as first-order risk measurement. As these CROs saw it, the creation of an aggregate view of quantified risks was the key benefit of implementing firm- 
wide risk models. It took considerable modelling expertise to extend risk analytics to uncertainties with explicable (but not yet known) properties and to adjust measurement approaches as further data became available.

Furthermore, Bank C's CRO advocated a role for risk analytics in managing the business's profitability. His rhetoric contrasted his own risk-management style with that of rival banks:

The question that you have to ask is: What do chief risk officers manage? Do you manage towards your capital base? Or do you manage towards your P\&L? [Rival global bank] had such a huge bottom line. So they can afford I think $\$ 16$ billion of credit losses, which they had. [Another rival bank] can afford to have $\$ 10$ billion of credit losses in their recession, but we can't... [...] I cannot lose more than [a few] billion. Just think about what it means for my risk policy. It means my margin of error has to be below 10 basis points. Therefore, [Bank C] needs to have an extraordinarily high risk-awareness.

This type of boundary-work (“expulsion”) is familiar from Gieryn’s (1983) study: The flattering contrast with rivals helps the ideologist to assert his authority by making the source of his expertise — in this case, risk analytics—-look inevitable and unavoidable ( "Bank C needs to have an extraordinary high risk-awareness"). The role of risk analytics was to fine-tune risk control; the justification was that the bank could not afford mistakes in risk-taking that its larger rivals could get away with. The CRO and his team put a great deal of effort into model-building and claimed they had solved the quantification problem:

Quantitative tools work particularly well in market risk, retail banking, and in lending to small commercial companies. The question is, what is our aggregate view of risk? In other words, what can hit the P\&L in any quarter? In order to answer this, we need to have a common denominator and you need to quantify things whether you like it or not. So you cannot avoid the model discussion. [In Bank C] right now, the common denominator is economic capital.

However, they also thought carefully about where to draw the boundaries of risk quantification and aggregation. Although they developed first- and second-order measurements for both market and credit risks (and calculated the economic capital commensurate to the aggregate of market and credit risks in the business lines), they felt that operational risks were incompatible with the economic capital framework and that operational-risk control should be the responsibility of a separate staff function (quality management): 
Quantifying operational risk is basically a flawed thing because it is like measuring road safety risk in terms of traffic and the death toll. But the death toll is a function of whether the road was safe, whether the drivers drove too fast, and so on. So counting the death toll misses the point, and similarly, you cannot control operational risk with capital. That is just kind of a fine. It doesn't trickle down to the businesses, it does not create incentives to operate without flaws. What you really need to do is in order to address this, you need to have a Six Sigma or a quality management initiative.

This type of boundary-work shows the ideologist advocating a focussed approach: Bank C's CRO strengthened the position of the risk function not so much by expanding its claims on new areas of uncertainty (unlike Fraser's CRO, he left operational-risk control to other constituents), but rather by fortifying his claims on existing territories.

Bank C's CRO was concerned not only with risk aggregation, but also with the linkages between different risk types, such as market risk, credit risk, and country risk. Initially, this concern was driven by the need to model correlations across risk types; Bank C's experience had shown that, in a crisis, the correlation between risks went up and the expected benefit from diversification shrank. At the same time, the risk team was staking its claim to the previously unexamined regional interdependencies that manifested themselves in correlation spikes in the 2008-9 financial crisis. As the head of country-risk management observed: "If you had had market-risk management, treasury, and credit this aligned three years ago (even in individual transactions), you wouldn't have had such a big calamity. You would have seen the [correlation] risks earlier.”

During the credit crisis, the CRO established a new risk committee, the Cross-Risk Review Committee, to discuss risk issues and a new function, portfolio management, to aggregate risk exposures across countries and portfolios. The senior risk officer heading this effort asserted:

\footnotetext{
Compared to our peers, we are able to see an aggregation of risks in [Bank C]'s portfolio, and that encompasses all businesses. So [Portfolio Management] is global in its mandate. As in any big organization, you have pillars. Some people call it silos; I think that's a given. I think the distinct feature of having a Portfolio Management function is that you actually cross those silos. ... We do an aggregation of all the risks, then we find out what resources the bank has. We can tell how much risk there is within the corporate bank by region, by counterparty, by country. That helps reporting the bank's exposures.
} 
Bank C’s risk experts had thus extended second-order risk measurement into a hitherto untouched domain (correlation analysis) while fortifying their credibility, which the previous lack of correlation-analysis might otherwise have undermined.

During the credit crisis, the CRO's attention also turned to providing the board with timely information on Bank C's largest risk exposures. To take on this role, he was willing to compromise the "correctness" of the risk aggregations for the sake of their timeliness:

I have my nine largest positions which can impact the P\&L with half a billion of hits over a quarter. That is my daily report. Every day at 9:00 I get that. So I know basically all of these positions by heart. .... But my numbers do not go through the independent price-verification process which is very important for financial reporting, in these times for instance when you don't have good market process [for market-to-market accounting]. But that process takes too long. That process takes us till the fourth quarter plus almost a month. I need results now. So therefore I take the risk that my numbers may be wrong.

This departure from the quantitative enthusiast's normal concern with the accuracy of risk models reveals another type of expansionist boundary-work: By emphasizing the relevance of risk numbers over their reliability, Bank C's CRO earned access to board-level discussions of key risk exposures during the credit crisis. While rival experts abstained from using financial data that had not been vetted through an independent verification process, he was able to differentiate risk management as the source of the timeliest information. This flexible boundarysetting recalls Gieryn's example of the Victorian physicist John Tyndall, who put science on the cultural map of nineteenth-century England. Just as Tyndall would emphasize either that science was more practical than religion or more theoretical than engineering (Gieryn, 1983, 1999), depending on the occasion, the CRO offered information that was either more accurate than those of rival banks' risk functions or more timely than those of Bank C's other staff functions. Where Tyndall's boundary-work enlarged the authority and resources of Victorian scientists, the boundary-work undertaken by Bank C's CRO enlarged his prestige and influence in board-level strategic discussions. By 2010, he was widely considered a likely candidate to become Bank C’s CEO.

\subsection{Summary}

For Fraser Bank and Banks A, B, and C, the keystone of risk control was risk measurement. While Fraser extended first- and second-order risk measurement into a wide expanse of uncertainties (described as market, credit, and operational risks), the other banks concentrated on 
measuring and aggregating market and credit risks only. Even so, we saw that the boundaries of risk management in these firms were ambiguous and flexible; they could be disputed (at Fraser), opportunistically compromised (at Fraser and Bank C), and even redrawn by the risk function itself (at Bank C when the CRO abdicated from the ultimate responsibility for operational-risk control).

Boundary-work not only expanded and demarcated the territory of risk control via measurement but could also protect the risk function's autonomy and exempt it from responsibility for the consequences of risk-taking in the business lines. As the CROs of Banks A and B mapped their worlds, the domain of risk measurements did not extend beyond normal and measurable circumstances. Any risk-management failure was the responsibility of business managers and board directors who failed to imagine and ask questions about non-measurable uncertainties, worst-case scenarios, and systemic risk problems, issues that were outside the boundaries that these CROs’ risk-management functions had constructed around risk control.

\section{Risk control via envisionment}

The following section summarizes the cases of Goethebank and two others (Banks D and E) that adopt an alternative style of risk control which does not privilege risk measurement over judgement and soft instrumentation ${ }^{11}$ and which I refer to as risk envisionment.

\subsection{Counting, control, and calculation at Goethebank}

Goethebank’s risk-management function took a path different than Fraser’s. Created within the group finance division, it reported to the chief financial officer (CFO) and secured visibility and status with the executive board early on. The CRO initiated and set the agenda of the board's Risk Management Committee, held monthly in conjunction with the Credit Management function (also part of the CFO division). Credit Management was by far the largest staff department, pulling together lending information from a staff of 1,430 located mostly in the branches. The CRO, with

\footnotetext{
${ }^{11}$ Soft instrumentation refers to decision making methods that do not privilege measurement. The decision maker's mental models, prior experience, beliefs and values are important complementary elements of decision making under uncertainty. Soft instrumentation privileges concepts of adaptive control, robustness, scenario planning and worst-case analysis (Kleindorfer, 2010).
} 
his 30 or so headquarters-based staff, was able to secure joint board-level visibility with the head of this well-established and powerful function:

We say we want to discuss employee benefit schemes in [home country] or we want to discuss issues of banking secrecy or whatever we think is of importance to those guys.

At first glance, Goethebank's risk function mobilized risk technologies similar to those observed in the previous four cases: three risk silos-market-risk controlling, credit-risk controlling, and operational-risk controlling-undertook first-order measurements which the economic capital subdepartment aggregated across each subsidiary (second-order risk measurement). The CRO reported both sets of results to the board, but did not consider the known, measured, and neatly charted risks to be the key ones:

The big risks today are: Are we running the right strategy or not? What do we do with private banking going forward? Should we grow retail banking [domestically] or rather abroad? Now, how do you integrate these into the monthly risk report?

It is remarkable that Goethebank's senior risk officers took part in the discussion of corporate-level strategies. When I suggested to the CRO that his people might be encroaching on the territory of the strategy and finance functions, he replied briskly: "Not if you have a chief risk officer. Because that's what you pay him for.”

Senior risk officers at Goethebank defined wide boundaries for the risk concerns they cared and reported about, including both measurable and non-measurable risks. Because the bank was recovering from a series of strategic mistakes and financial losses, top management was much more inclined to listen to a new voice in strategic control that was not only measuring the measurable but also envisioning risks which could not be measured but which certainly might be encountered. ${ }^{12}$ The CRO reflected:

We [the three most senior risk officers of Goethebank] have discussions about what the most dangerous things that could happen are. We put together a report to the board about these and what we do against them. ... It could be the quality of the [domestic] lending portfolio, given its sheer size. It could be the impact of an interest-rate increase on the asset portfolio of [Division X]. It could be further erosion, further defaults in the energy sector in the U.S.

Senior risk officers obtained strategic information directly from the business lines in regular face-to-face meetings. For example, the CRO of the group's insurance business unit instigated “special risk reviews" to be presented to divisional risk-management committees by line-

\footnotetext{
${ }^{12}$ This observation supports Simons's (1991) thesis that, at a time of financial crisis, top management is inclined to use multiple control systems interactively.
} 
management staff on diverse topics often designated as "specific strategic issues." According to the meeting schedules, quantitative risk analyses received 15-30 minutes of attention, while special risk issues were discussed for 45-90 minutes. The latter could not be quantified, but were discussed in light of the expertise, experience, and judgment of the regular attendees and the invited speakers.

In contrast to Fraser Bank’s quantitative enthusiasm, the characteristic feature of risk quantification at Goethebank was a strong scepticism (Mikes, 2009a). Although market and credit risks were modelled, risk measures were treated as trend indicators rather than as expressions of the underlying economic reality. Nowhere was the contrast more apparent than in the treatment of operational risk. Unlike market and credit risks, many of which were deemed as a priori known or statistically classifiable into homogeneous categories of occurrences (e.g., defaults occurring in a certain credit card segment), operational risk presented a dilemma. Are the losses resulting from inadequate or failed internal actions and processes or from external events statistically knowable or inherently unmeasurable? It was a telling sign of the quantitative enthusiasm of Fraser's risk managers that they classified a growing number of operational risks as statistically measurable. In contrast, Goethebank’s managers and senior risk officers considered operational risk to be largely unmeasurable. The operational risk director was not a risk analyst, but rather a "traditional banker" who had spent much of his career in operations. He was very critical of the regulators' plan to encourage banks to measure operational risk and set aside adequate (economic) capital against it:

I am not a fan of the quantitative approach in operational risk. I don’t know if I should put all my effort into risk measurement to quantify, [given that] when it really happens my figure would be for sure completely wrong. So why should I put all my resources into something that is senseless?

Based on his extensive operational experience and relations within the bank, he cultivated an advisory and collaborative relationship with the business-unit risk managers, which encouraged them to report operational losses (over a certain threshold, as and when they occurred) into a loss database. This was used to prepare post-mortems and periodic special risk reviews of loss trends. The operational risk director left the boundaries between risk control and operational management porous and passable; in order to learn about near misses and turn risk control into a learning exercise.

Although Goethebank adopted the economic capital methodology to calculate the aggregate risk profile of the group and its business units, top management credited these numbers only with indicating the underlying risk trends, not with capturing the risk profile in any absolute sense. For example, during the 2002 European insurance crisis, Goethebank’s economic capital team picked 
up a worsening trend in the equity portfolio of the insurance division. However, corrective action took place only after it became clear that the P\&L account had suffered, too.

This experience led the economic capital team to make a “raid” on another function's territory that was uncharacteristic of an envisionment culture but nevertheless instructive. Noting that second-order risk measurements (economic capital calculations) had been more successful in detecting the insurance company's crisis than accounting controls, the head of the team proposed to make economic capital a cornerstone of performance monitoring. He immediately found himself in a credibility contest with the strategy and control department, traditionally the bank's guardians of management accounting and performance monitoring. From their point of view, there was already an accounting control available for the insurance division's risk capacity-the regulatory capital metric, ${ }^{13}$ a well-established regulatory tool which derived its legitimacy from its US GAAP basis. Unlike Fraser Bank’s planners, Goethebank’s performance-management function felt that risk calculations (second-order risk measures in particular) lacked the administrative objectivity of profit-and-loss accounts. They did not welcome the proposed risk-based performance metric as a complementary control tool, but rather resented it as a competing one. As the head of this function put it: "Anybody who would have been interested in reading the numbers could have learned a lot out of them without any fancy calculations of [economic capital].” The head of the economic capital team realized, like his unsuccessful counterpart at Fraser, that risk numbers-however valid—would not necessarily work by themselves; they had to be made to work:

We could calculate Economic Profit, but if we did, nobody would want to have it in the Strategic Business Plan that goes to the board. ... [The strategy and control function], for example, does not support it.

While Goethebank managers did not assume that accounting figures reflected the underlying economic reality, accounting had been black-boxed and was taken for granted, while risk calculations lacked "precision, even a certain fake precision, [that] confers an administrative and pragmatic transparency” (Power, 2004a:770), which both the controller and the controlled could have used to reach a fair bargain in capital allocation and performance management.

All told, Goethebank's three CROs were less concerned with measurable risk types than with the unmeasurable. They made little effort to push the boundaries of risk management into

\footnotetext{
13 The solvency ratio of an insurance company is (most often) defined as the size of its capital relative to net premium written. The solvency ratio is a measure of the risk an insurer faces of claims that it cannot absorb.
} 
"rival territory."14 Instead, they moved into areas that had been left unoccupied. Searching for critical data that could not be readily quantified, they succeeded in claiming relevance in the discussions preceding major strategic decisions. Their role at the time of the case study was to (a) regularly set discussion agendas for top management and (b) collect expert views on special risk issues. Goethebank's case demonstrates that risk control is possible even when the quantifying spirit is muted or sceptical. This envisionment style of risk management (and its accompanying boundary-work) de-emphasizes the ideal of risk management advocated by regulators and by the CROs of Fraser and Banks A, B, and C. Instead of turning uncertainty into measurable categories of risk, this approach manages uncertainty by articulating alternative futures and their implications for the business in order to support wider discussion and debate among decision makers.

\subsection{Risk control via envisionment: Boundary-work}

Between 2006-2010, I studied two other banks where senior risk officers de-emphasized risk measurement and asserted that risk management was more art than science. Their ideologies suggest that "risk management" is no single thing; the characteristics attributed to it vary widely with the specific professional ambitions of risk practitioners.

\section{Bank D}

Bank D operated in retail banking, commercial banking, and investment banking. It prided itself on its long history of surviving turmoil in some of the most challenging markets in the world. Bank D’s management had traditionally taken a "conservative stance” towards risktaking. The chief risk officer explained that this risk-averse approach was a blessing in bad times, but a curse during boom periods:

Our risk-management philosophy is actually about limiting downside rather than optimizing upside, which is why when things are going swimmingly we tend to underperform the market and we're conceived as horribly conservative, boring, under-leveraged. [But] we have demonstrated survivability in the face of potential nasty things that can, and do, happen. How does that translate into day-to-day business decisions? It means you have a diversified portfolio both by geography, by line of business, by product group, so that if one bit goes wrong, then not everything is correlated, you hope there will be a pick-up in something else. The downside is, of course, it means that to get all cylinders at one time firing at $100 \%$ is exceedingly difficult.

\footnotetext{
14 The economic capital team's effort to replace the insurance company's accounting controls with its own controls was not supported by the CROs and the head of that team withdrew his proposal and left the bank.
} 
He regarded the use of risk models in this culture with much scepticism:

Here, [making risk decisions] is much more about judgment. Clearly we use models (a) because we have to, (b) because they are an aid to judgment, but if you went back-we were quite late to the model game. I still regard them with a high degree of circumspection. Well, thinking you can transform the laws of the natural universe into the laws of human behaviour is a tremendous leap of faith.

Like Goethebank’s CROs, Bank D’s risk cartographers avoided claiming access to performance measurement, due to their own scepticism about its technical (and perhaps political) feasibility. Instead, realizing that powerful economic incentives created perverse effects on managers' risk-taking behaviour, especially at the uptick of the economic cycle, they defined their role as the nagging voice of conscience in planning and strategic reviews, playing the devil's advocate to business units eager to grow.

At quarterly review meetings in which the CEO, CFO, CRO, and heads of the main business lines reviewed the performance of country managers, the CRO articulated the regulatory capital needs in light of the apparent growth and risk-taking of the business lines. The credit crisis made capital-management issues much more relevant to key strategic discussions:

Exceeding your asset growth in your plan in the first two months of the year used to be a big pat on the back. Now, you've got to explain it. It may still be a good thing, but it will no longer be considered as clearly the smartest thing in the world. (A) You have to ask for more capital but (B) you have to ask yourself why are you doing so well? [...] Why does your market share suddenly go up from $7 \%$ to $30 \%$ ?

However, this reliance on the capital-management lever was conditional on what another senior risk officer called "the cultural position of the risk function" at a particular point in the economic cycle. He reflected on the inevitable cyclic erosion of risk discipline:

I call this condition creep. What was a no-no two years ago suddenly becomes acceptable, because everyone’s now getting more liquidity, more drive, and more capacity to lend, and you suddenly end up taking more risk. And that's what's happened in the U.S. property market this time around. The market has just gone from an extended period of a benign environment all the way back to correction. But it's really difficult for us [risk managers] to call it, to be the first one to call it, to back off. Because there are no prizes for CEOs of local businesses to take an overly conservative approach to their business. They're paid on results; they're paid on how many millions of dollars they are going to give us [the group centre] by way of dividends. That's why, in my view, corrections will always happen, always. 
Prior to and during the financial crisis, Bank D’s senior risk officers only had an ad hoc involvement in the annual planning process, which they had recently sought to formalize by linking the capital-management discussions (and their devil's advocate role) to that process. However, including risk-capital projections in the pro forma business plans required the risk function to produce numbers with administrative objectivity similar to that of the accounting numbers that had traditionally driven the planning process. The CRO still took these projections with a pinch of salt; their administrative objectivity, like that of the assessments of large risk exposures which Bank C's CRO presented to its board, was derived from their usefulness in the planning process rather than their absolute accuracy:

We are now actually getting in front of the planning process rather than coming along behind it. [...] You've got to guard against growth in concentration, you've got to ensure that you set out to build diversification, you set out to allocate capital where you think the highest growth opportunities long term may be. We'll have some quantitative risk objectives but within sufficiently broad bands. We think the numbers are probably directionally correct, but I wouldn’t bet my life on them being precise.

Minimum regulatory capital requirements were a biting constraint during the global financial crisis and Bank D anticipated that, due to expected regulatory changes, they would remain so. Thus, senior risk officers drew on an external compliance and legitimacy requirement to expand the boundary of risk management into a domain that had hitherto been claimed by the planning function. Nevertheless, they were aware that this move was somewhat opportunistic and that the cultural space they occupied was liable to change shape later in the economic cycle when capital management would not seem as important.

\section{Bank E}

Bank E was a medium-sized international bank focusing on retail and commercial banking opportunities in fast-growing emerging markets. Over the last 10 years, the share of commercial banking in its portfolio had grown steadily. The corporate bank's core strength was to initiate and manage large, close-to-a-billion-dollar "transformational loans" to fast-growing companies in emerging markets, but management understood that, if any of these loans went bad, the bank could be destroyed. In this context, the risk-management function not only provided oversight on risk taking, but was also required to sign off on each deal. Some of the uncertainties were amenable to modelling; for example, each potential borrower received a 
quantitative credit rating based on a default probability calculated from multiple risk models. However, senior risk officers considered the financial aspect of credit risk an insufficient proxy for the risk they would actually be taking, which included many qualitative concerns. The deputy-CRO explained:

The best lending decisions I've ever made have been the ones where I said, the financials look pretty good, but there are some funny things going on here. The example I would give: There was a proposal to lend to a sugar company. Revenue was $\$ 1$ million; it looked great. But sugar is one of the most highly politicized, the most highly subsidized commodities worldwide. I looked at this thing — it was in the U.S.—-and I said, if the sugar subsidies ever go away here, this thing is dead as a doornail. I just don't want something in my portfolio that entirely relies on political will. Lo and behold, the sugar subsidies went away, and the company died. People grumbled when I turned down the deal and nobody gave me a high five when the company went under, but it went under. And it's just one of those things. Again, the key learning decisions you make are not based on what you put in the model and what gets spat out, it's-what's going on here, what are the changes in the industry, is this something we should be in? Another example: Eastman Kodak went into bankruptcy — there was nothing in the financials, until it was too late, that said they were going to go bankrupt. But if you put the digital photography on the horizon, you might say-well, geez, maybe we don't really want to be in this.

Bank E’s senior risk officers focused on risk anticipation, believing that the output of risk models could only indicate trends. A former chief risk officer of the wholesale lending division asserted that forming a view about emerging risks was the ultimate task of the risk officer:

You get into that habit of thinking forward. My view as CRO of the wholesale bank was always what the environment was going to be like three years out, because if I needed to change the composition of my portfolio, I'd have to start two years before.... A model is a tool that you should be comparing with what you expect to see.... Finding out a model doesn't work anymore isn't a good way of finding out there are changes in the background that you should adjust to.

\section{Bank E’s chief credit officer was a vocal advocate of tacit knowledge:}

[If you are a relationship manager trying to persuade me that I should sign off on a loan to your client], you never have a short meeting with me. I'm finding out more and more about you, and how you tick and how you work, so I can position myself in a way to be able to deal with what you're going to bring to me.... I need to know the business generators well enough to know when they're likely not to tell you the truth, to know that their own stance and emotion and the fervour for a deal will impair their judgment. Most people, most very successful deal-doers, will always push the envelope. The issue is to understand how they operate within their values. So not only do I understand where they're likely to over-egg it because the rewards are there, but also it will tell me how to approach them when I want to slow them down. 
For such risk officers, formal risk models were helpful but not decisive. Each operated a mental model (Kleindorfer, 2010) of the key risk trends he watched, as described by Bank E's chief credit officer:

What I would normally do is when I think about something, I'll put mental markers down, and say: If the trend is going this way, this will happen, then this will happen, then this will happen. And the moment I see three of those pillars knocked down, I know that we're going in the direction I thought we were. That way I can start taking action once I've got those confirmations it's going in that particular way. Before that, I adjust but I adjust quietly and little by little. Once I have got confirmation it's going that way, I can be a little bit more vociferous, and I usually have the discussion with the senior business generators as well. So they are watching those elements as well. So when they see them happen, they know I am going to be coming and ratcheting down.

Bank E’s senior risk officers enjoyed formal authority and displayed much confidence in playing the devil's advocate when negotiating business proposals. They contrasted their role to the roles of their peers at other banks, whom they saw as fire-fighting after the risk events took place because they lacked the pre-approval decision authority and the means of being influential before a deal. As the previous interviewee commented:

It is amazing how many risk people you can fool and how many are prepared to believe what you tell them without testing it. It's one of the skills I find less and less present in risk officers: that absolute cynicism and total disregard for asking a stupid question. If you aren't a confident individual, you're never going to ask a naive question. And the reality is, the question you need to ask is the naïve one. [Comment on users of risk models:] I think their cynicism is not informed cynicism. It's theoretical, which means the individuals don't hold any degree of cynicism. They question because they're supposed to, not because something doesn't make sense.

This type of boundary-work demarcated a style of risk management, which was based on probing and questioning from other categories of "theoretical" risk management that lacked “informed cynicism”. It resulted in the growing influence of Bank E’s senior risk officers on business decision makers ex ante-before large risk-taking deals occurred. Risk management at Bank E took place in what could be called a pre-approval mindset, whereas much of the risk management at the other banks took place post-approval.

The deputy CRO was particularly critical of his peers' attempts to classify risks into risk types (market, credit, operational):

The danger is that we have compartmentalized risk too much. There is market risk, there is operational risk, there is reputational risk, there is credit risk-all separately discussed and managed. But the reality is: They all interact. At the Group Credit Committee, I look at deals 
from a credit-risk perspective, but I have to tell you, I'm certainly looking at country risk and reputational risk as well. Risk management is chemistry, not particle physics. You cannot separate the risks.

Bank E’s senior risk officers engaged in the type of boundary work Gieryn (1999) labels expulsion — demarcating one’s field "from various categories of posers" (Gieryn, 1999:16). Here, the goal was not the expansion of their authority, such as we saw in the previous cases, but rather the monopolization of professional authority as risk managers, excluding rivals from within the emerging risk profession who privileged risk classification and measurement. They constructed a boundary between themselves and other risk professionals who were engaged in "compartmentalizing risks," who were "theoretical" rather than "informed," whose "particle physics" approach to risk management exposed their firms to the downsides of a siloed view of the risk universe.

\subsection{Summary}

This explicit deference to human judgment rather than to modeling was in striking contrast to the calculative enthusiasm displayed by the senior risk officers of Fraser Bank and Banks A, B, and C. Those displaying quantitative enthusiasm strove to capture the complexity of risk decisions in the model design, including as much judgment as possible upfront, so that the model's output could be regarded as a close proxy to the underlying risk profile. For these risk managers, models that have gained enough legitimacy — which have been black-boxed—reduce decision uncertainty by leaving less room for disagreement among decision makers on the validity of the model's output.

In contrast, the risk officers displaying quantitative scepticism at Goethebank, Banks D and $\mathrm{E}$ operated somewhat simpler models; relationships not captured in the model design were to be considered ex post. Where the director of risk methodologies at Bank B felt that "if you can't capture all risks pretty comprehensively and measure them consistently, then no matter how skilled or experienced your people are, there's going to be a limit on how good they can make their decisions, because they're not looking at the true picture," the former CRO of Bank E's wholesale bank was convinced of the need for "thinking forward . . . Finding out a model doesn't work anymore isn't a good way of finding out there are changes in the background that you should adjust to." Bank B's director of risk methodologies pointed out that "I'm not the person who made those calls [leading to losses during the 2007-2009 credit crisis]. I'm not the person 
who even suggested they [the board] make those calls, you know, because it's not my job.” But Goethebank's CRO pointed out that he and the other most senior risk officers "have discussions about what the most dangerous things that could happen are. We put together a report to the board about these and what we do against them.”

While risk officers focussed on measurement drew a boundary between what they did and the downstream consequences of decisions made with (or without) their recommendations, those deploying risk envisionment actually expanded their areas of responsibility.

At the same time, they increased decision uncertainty by challenging decision makers to treat the model output as the starting point for further inquiries and the exercise of judgment. The quantitative sceptics I observed made it clear that they did not aspire to conquer all of the measurement challenges that quantitative enthusiasts set for themselves. In particular, they were not, at the time of the study, aiming for risk-adjusted performance measurement. They sought a different kind of influence: drawing on decades of business experience and their intuitive sense of “danger signs” to anticipate emerging risks, they guided (and, in the case of Bank E, made) strategic decisions, for which they were ready to take responsibility.

\section{Discussion}

\section{Patterns in metrological dramas}

Despite similarities in their structural arrangements and risk-management techniques, risk functions in different organizations play out their own characteristic metrological dramas. Table 1 illustrates this point for Fraser Bank and Goethebank.

\begin{tabular}{||l|l|l||}
\hline $\begin{array}{l}\text { Acts in the metrological } \\
\text { drama of risk management }\end{array}$ & Fraser Bank & Goethebank \\
\hline Establishing formal status & $\begin{array}{c}\text { Evidenced: Reorganization enhances the } \\
\text { formal status of “risk-counting experts.” }\end{array}$ & $\begin{array}{l}\text { Evidenced: Recurring changes to } \\
\text { committee agendas enhance the } \\
\text { visibility and influence of the risk } \\
\text { officer as "strategic advisor.” }\end{array}$ \\
\hline First-order risk measurements & $\begin{array}{c}\text { Expansion of measurement: market risk, credit } \\
\text { risk, operational risks (advanced approach) }\end{array}$ & $\begin{array}{l}\text { Basic metrics for market risk, credit } \\
\text { risk, operational risks (basic approach) }\end{array}$ \\
\hline Second-order risk measurements & $\begin{array}{c}\text { Credible economic capital calculations } \\
\text { through protracted work }\end{array}$ & $\begin{array}{l}\text { Economic capital calculations deemed } \\
\text { as compliance-driven }\end{array}$ \\
\hline
\end{tabular}




\begin{tabular}{||l|l|l||}
\hline $\begin{array}{l}\text { Control through risk-adjusted } \\
\text { performance measurement }\end{array}$ & Evidenced & Not evidenced \\
\hline $\begin{array}{l}\text { Risk officers' regular and frequent } \\
\text { influence on key strategic decisions }\end{array}$ & Not evidenced & Evidenced \\
\hline
\end{tabular}

Table 1. Comparison of the patterns of metrological dramas of risk management at Fraser Bank and Goethebank

Both banks introduced risk-management functions in the wake of a crisis. In both banks, those functions gained formal status and visibility through the appointment of senior risk officers and the establishment of reporting channels to the board. Both functions were successful in introducing new first-order risk measures (e.g., value-at-risk) and both regularly produced specialist risk information for top management and the board.

At Fraser, economic capital, a second-order risk measure, filled a gap in value-based management by offering a risk-based measure of capital charges. Nevertheless, economic capital calculations had to be made to work by balancing the reliability and relevance of risk calculations with the fairness and internal legitimacy of the process.

The legitimacy of risk measurement was thus not immediately self-evident; it was constructed. The idea at Fraser that economic capital numbers reflected the true risk profiles of business units may have been a myth, but that did not make it any less powerful. Risk managers had constructed the legitimacy of risk-based performance management. They fostered and reinforced a culture of quantitative enthusiasm, which was shared by a host of external onlookers: riskmanagement peers who advocated economic capital as a best practice and bank regulators who actively encouraged the expansion of risk quantification into new realms of uncertainty.

Although risk calculation effectively redefined performance measurement at Fraser, the influence of the risk function stopped short of key strategic decisions, which (theoretically) were in the realm of the unmeasurable and (in practice) were claimed by the powerful planning function. By declaring its remit to be the quantifiable risk universe, the risk function was excluded from top managerial discussions of strategic uncertainties.

In contrast, the language of economic risk at Goethebank failed to redefine the planning and performance-measurement processes. In that management environment, risk calculations (secondorder risk measurement such as economic capital modelling) were not seen as having the administrative objectivity of profit-and-loss accounts and statutory solvency metrics. Goethebank’s senior risk officers concerned themselves less with the measurable risk types than with the unmeasurable. Searching for critical data that could not be readily quantified, they secured 
relevance in the discussions preceding major strategic decisions. Their role, at the time of the case study, was to regularly set the discussion agendas for top management and to informally collect, share, and distribute information.

The mode of questioning and investigation they brought to top management discussions was not diagnostic. Instead it was interactive (Simons, 1991) and these senior risk officers positioned themselves as “self-reflective and self-improving” organizational actors (Power, 2007:23). They shifted the concept of risk management from a disciplinary and backward-facing practice involving narrowly defined technical expertise for the counting of risks to a forward-looking and anticipatory practice providing knowledge leadership and strategic advice to top management, proving that, even without elaborate calculations, risks can count.

The regulatory imperative should not be underestimated as a driver of coercive isomorphism in the banking sector. Due to the compliance imperative, the risk functions I observed at seven banks between 2006 and 2010 were engaged in similar risk-management projects, which included developing risk measurements for market, credit, and operational risk and an economic capital approach for the internal allocation of capital.

The senior risk officers I interviewed had divergent opinions on the benefits and limitations of the available risk-modelling initiatives. CROs at Fraser Bank and Banks A, B, and C were committed to extensive risk modeling and fostered a culture of quantitative enthusiasm in which risk models were regarded as robust and very relevant decision-making tools, particularly for planning and performance management. In these banks, "risk-counting” experts gradually expanded the modeling infrastructure to uncover the natures and distributions of hitherto unknown uncertainties and classified and measured these as part of the operational-risk category. Once these additional risk assessments became part of the risk-measurement framework, they influenced the aggregate risk calculations (economic capital). But linking these risk calculations to planning and performance measurement was not automatic. Senior risk officers were aware that their numbers had to be made to work - a political rather than a technical challenge.

There was an alternative approach to risk control that did not privilege risk measurement but rather focused on the envisionment of decision-relevant risks. Risk officers at Goethebank and Banks D and E attempted to mobilize judgment and soft instrumentation to provide top management with alternative future scenarios and with expert opinions on emerging risk issues. Their quantitative skepticism de-emphasized risk models in decision making; they saw their roles 
as devil's advocates, searching for relevant intelligence and channeling it to the apex of the organization.

\section{The boundary-work of risk experts}

The second stage of my research sought to shed further light on the boundary-work underlying the efforts by risk officers to claim relevance in the control and management of risks (Table 2).

\begin{tabular}{|c|c|c|}
\hline $\begin{array}{l}\text { Sites of additional field } \\
\text { work }(2006-2010)\end{array}$ & Banks A, B, and C & Banks $D$ and $E$ \\
\hline $\begin{array}{l}\text { Perceived accuracy of risk } \\
\text { information }\end{array}$ & $\begin{array}{l}\text { Accurate enough for performance } \\
\text { measurement }\end{array}$ & Indicative of trends only \\
\hline $\begin{array}{l}\text { Role of judgement } \\
\text { in risk modelling }\end{array}$ & $\begin{array}{l}\text { Model design contains the } \\
\text { modeller's judgement. }\end{array}$ & $\begin{array}{l}\text { Model design deliberately simple. } \\
\text { Managerial judgement is exercised ex post. }\end{array}$ \\
\hline $\begin{array}{l}\text { Calculative culture } \\
\text { displayed by senior risk } \\
\text { officers }\end{array}$ & Calculative enthusiasm & Calculative scepticism \\
\hline $\begin{array}{l}\text { Economic capital linked to } \\
\text { strategic planning? }\end{array}$ & $\begin{array}{l}\text { Yes (with the exception of Bank A, } \\
\text { where this was regarded as a "work in } \\
\text { progress") }\end{array}$ & No \\
\hline $\begin{array}{l}\text { Risk-adjusted performance } \\
\text { measurement? }\end{array}$ & $\begin{array}{l}\text { Yes (with the exception of Bank A, } \\
\text { where this was regarded as a "work in } \\
\text { progress") }\end{array}$ & No \\
\hline $\begin{array}{l}\text { CRO involvement in } \\
\text { discretionary strategic } \\
\text { decisions }\end{array}$ & $\begin{array}{l}\text { Low (with the exception of Bank C } \\
\text { where the CRO was a member of the } \\
\text { Group Executive Board) }\end{array}$ & $\begin{array}{l}\text { High } \\
\text { (experienced devil's advocate) }\end{array}$ \\
\hline Observed boundary-work & $\begin{array}{l}\text { Expansion of expertise into new } \\
\text { domains (market risk, credit risk, } \\
\text { operational risk). } \\
\text { Expulsion (see Bank C): Heightening } \\
\text { contrast with rivals to flatter the } \\
\text { ideologist's side (who can be "more } \\
\text { accurate" or "more timely" than rivals, } \\
\text { depending on perceived needs). } \\
\text { Protecting autonomy over risk-control } \\
\text { activities; limiting responsibility for } \\
\text { downstream consequences. }\end{array}$ & $\begin{array}{l}\text { Expansion of expertise into new domains } \\
\text { (planning and strategic decision making). } \\
\text { Expulsion (see Bank E): Heightening } \\
\text { contrast with rivals to flatter the ideologist's } \\
\text { side (who claim "informed cynicism" as } \\
\text { opposed to a "theoretical, } \\
\text { compartmentalized" risk management). } \\
\text { Leaving porous boundaries between the risk } \\
\text { function and the business lines; expanding } \\
\text { responsibility. }\end{array}$ \\
\hline
\end{tabular}

Table 2. Additional field work: Summary of findings 
Due to international bank regulations, banks opened a new space in the organizational landscape of control and endowed it with ample resources. Moving into this space under the banner of compliance, risk managers then started to define, expand, and redefine their remit by constantly shifting the boundary between yesterday's incalculable uncertainties and today's measured or envisioned risks. They also created rhetoric to fortify their claims on the control of the measured risks (at Fraser and Banks A, B, and C) and on the envisioned risks (at Goethebank and Banks D and E). Rarely did they step on the territory of others uninvited and, when they did, credibility contests ensued (as with the economic capital teams at Fraser Bank and Goethebank). In general, though, the cultural cartographers of risk management learned to adjust to the existing politics and tended to choose their battles carefully; expansion into performance measurement was only possible by working in alliance with the current occupants of that space and offering a complementary claim rather than a competing one.

Altogether, the lessons learned at the seven banks suggest that the boundary-work of risk experts is contingent on the calculative culture they display and can result in very different styles and dynamics of risk control:

On one hand, risk officers displaying calculative enthusiasm focus on risk control by measurement: the creation of second-order measurements, models that not only demarcate an aspect of performance (in this case, risk-adjusted performance), but also signify a distinct expertise which entitles the senior risk officer to a degree of organizational control. Such risk officers in this study invested heavily in extending the boundaries of risk control through risk models embodying firstand second-order measurements. They created new manageable realities (calculable objects) that could, in turn, be the objects of economic calculation (Barry and Slater, 2002). Within this category, we have seen the boundary-work of senior risk officers expanding their expertise to new areas of risk (expansion) and emphasizing contrasts with rivals to bolster the case for their use of first- and second-order measurements (expulsion). The ideological rhetoric of "independent and scientific" risk control protected their autonomy and helped them deflect criticism and displace blame in the face of apparent risk-management failures.

On the other hand, risk officers who take a fundamentally skeptical approach to calculation (quantitative skepticism) focus on envisioning risks: they mobilize a combination of first-order measurements and envisionment practices, based on their mental models, prior experience and intuition. Controllers in this camp lacked the analytical mystique wielded by those with quantitative 
enthusiasm and they appeared to have deliberately left the boundaries between themselves and the rest of the organization blurred and porous in order to influence decision makers in the business lines. What might be a weakness from the perspective of creating a distinct expert group, however, can be seen as a strength when it comes to working through organizational boundaries and "getting things done” in the business lines. In contrast, the first approach appeared to be more effective in terms of creating an independent and distinct expert function in the organization but its practitioners seemed to have limited relevance (or lacked the ambition to participate) in the discussion of nonmeasurable strategic uncertainties.

Senior risk officers displaying a strong quantitative skepticism expanded the boundaries of the risk universe beyond modelling by creating forums for the envisionment of non-calculable risk objects. Drawing a favourable contrast between themselves and "theoretical" risk managers (expulsion), they relied less on formal models than on their own cognitive-mental models, imagining alternative futures about which the existing models had nothing to say. They sought to anticipate emerging risks and non-measurable uncertainties in order to guide discretionary strategic decisions, for which they were ready to take responsibility.

\section{Implications for the development of risk management}

We have seen that the growth of risk management via measurement in banking is not inevitable; it is contingent on calculative cultures and risk experts' boundary-work. It is not really “risk management" that is steadily staking out new territory, but a variety of risk managements.

The existence of alternative plots in the metrological dramas of risk management suggests that there is nothing inherently "dangerous" in risk management. However, there is a need for a reassessment of stakeholders’ expectations of risk management. Frank Knight’s classic typology (Knight, 1921) is relevant here: While the realm of financial risks is tied to known (Type I) uncertainties, where the outcomes stem from a priori known distributions, the aspiration to control all material risks pushes the boundary of risk management into the fuzzy field of "statistically knowable" (Type II) uncertainties, where the outcomes stem from currently unknown but statistically knowable distributions, and “unmeasurable” (Type III) uncertainties, where distributions are nonexistent.

Over the last decade, a growing number of practitioners and commentators have been recasting a firm’s strategic, IT, legal, and compliance uncertainties as additional and distinct risk 
categories (Economist Intelligence Unit, 2005; PricewaterhouseCoopers, 2007). If risk officers are to uphold the ideal of measurement, they can only extend their remit to risks that can be described by a priori known or statistically knowable distributions. Alternatively, if they are to discuss and influence the management of non-quantifiable risks, threats, and opportunities (Knightian uncertainties), they have to venture outside the measurement framework.

Theoretically, the strategies suggested by this dilemma are not mutually exclusive; alternative calculative cultures could co-exist within the same organization so that the envisionment-based risk framework could co-exist with measurement-based risk control. But developing each requires very different sets of expertise. While risk quantification requires adequate risk-measurement and aggregation technologies, risk envisionment requires the risk manager to formulate mental models based on informed judgment and prior experience.

We see in our examples that practitioners have understood this problem as a choice and acted accordingly. Some stuck to the path of building measurement-driven, quantitative riskmanagement practices and occupied themselves with the computational task of "risk measurement" and the political task of making these measurements count in performance measurement; that is, counting risk and making risk count. Others addressed the unmeasurable (while maintaining a basic compliance framework) and developed practices of risk envisionment. By de-emphasizing processes of measurement and expanding the processes of interaction and dialogue, they have shown that risk management is possible outside Power's (2004a) framework of counting, control, and calculation.

\section{Directions for future research}

The distinction between measurement and envisionment needs further exploration. Sociologically oriented accounting studies have long argued that numbers are narratives, used to communicate visions of what there is, what might happen and what might be done about it (Lavoie, 1987; Hopwood and Miller, 1994; Mouritsen et al., 2001; Vollmer, 2007). While there is no question that numbers are a means of communication, they are not the building block of $a$ language but rather of several possible languages. In this paper, for example, we see the distinction between first-order measurement and second-order measurement and the very different consequences of valuing first-order measurements as stepping stones to second-order measurements or as jumping-off points for the various practices I have described as 
“envisionment." For both advocates of second-order measurement and practitioners of envisionment, numbers are indeed narratives, but very different stories are told.

Future researchers have much to uncover, then, by exploring the role of first-order risk measurements in day-to-day organizational action and decision making. As we have seen, risk practices that mobilize first-order risk calculations appear to have the capacity to either increase or decrease decision uncertainty. At Frasers and Banks A, B, and C, where the ideal of risk aggregation and risk-adjusted performance management took hold, risk functions mobilize firstorder risk measurements to create second-order measurements. With these second-order measurements, the risk function envelops uncertainty in a system of standard formulae, making it feel safe and responsible for other functions to carry on routine work and decision making in the face of ambiguity. In stable environments, this might well be a benefit, conserving mental energy and keeping the organization's behaviour consistent. But in evolving environments, such systems may offer simplistic misdiagnoses and encourage organizational inertia, threatening the firm's competitiveness or even its survival. At Goethebank and Banks D and E, the risk functions mobilize first-order measurement and "softer instrumentation," such as playing the devil's advocate, raising questions about underlying assumptions, extrapolating trends into the future, and contrasting alternative scenarios with past experience - decision making practices which I have termed "risk envisionment." These practices increase the uncertainty of decision making and foster discussion and debate rather than offering clear guidance.

Such practices are familiar to management scholars who have documented devil's advocate systems (Janis, 1982) and interactive controls probing a firm's key strategic uncertainties (e.g., the "risk calculator"; see Simons, 1991, 1999). Furthermore, organizational theorists have long argued that innovative organizations in changing environments need information systems that destabilize the organization by acknowledging differing evaluations of the status quo and by subjecting existing beliefs to doubt (Hedberg and Jonsson, 1978). However, further field research is required (a) to document and catalogue a comprehensiverather than ad hoc-set of "softer instruments" which either are serving or could serve as alternatives to second-order measurement and (b) to explore and explain the conditions under which these tools are applicable and under which they should either complement or replace risk measurement practices. 
The financial disasters of 2008-2009 convinced some observers that counting-focused, model-based risk management has failed (Power, 2009). If it has, the fledgling practice of risk envisionment suggests that risk management has the capacity to reinvent itself yet again. This time, however, the focus is less likely to be on calculation than on "qualculation" (Callon and Law, 2005), a broader notion of calculation that would include activities-such as scenariothinking, war-gaming and playing the devil's advocate —normally considered the opposite of calculation. Collapsing the distinction between the quantitative and the qualitative would give envisionment the status of rational action which risk measurement enjoys. However, as Callon and Law predict, it will take effort to redefine calculation (risk measurement) to properly include non-risk-specialist judgment (envisionment practices). Such efforts are likely to take place at the microsociological level—inside organizations—and will be an essential topic of field research. But they are also likely to take place as part of the ongoing professionalization of risk management, a phenomenon that itself awaits research and critical assessment. As practitioners move forward, theoretical and empirical researchers will be summoned to account for new realms, new definitions, and new purposes of risk management. 


\section{APPENDIX}

\section{FIGURE 1.}

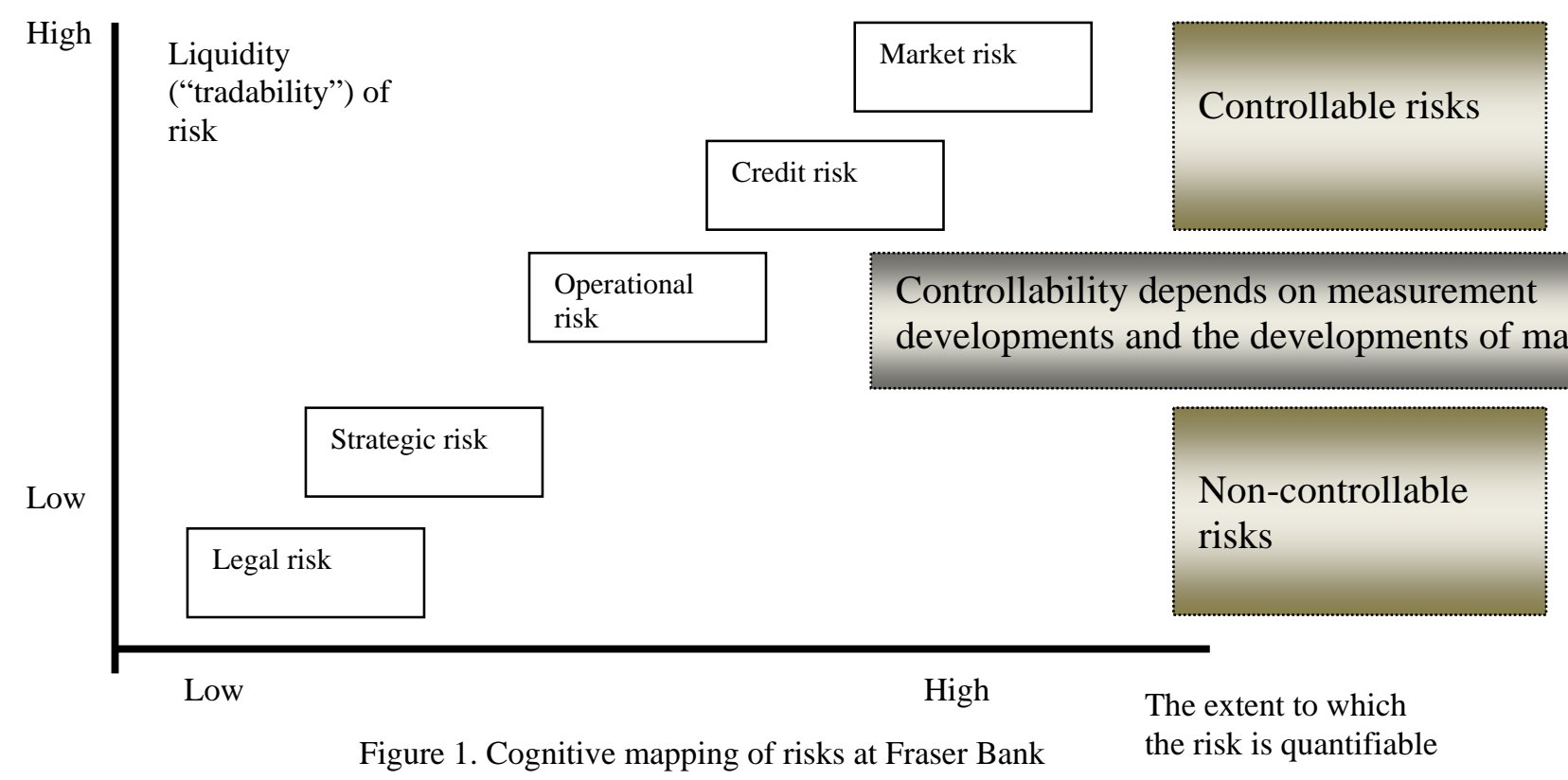

\section{REFERENCES}

Abbott, A. (1988). The System of Professions: An Essay on the Division of Expert Labor. Chicago, IL: The University of Chicago Press.

Ahrens, T. (1996). Styles of accountability. Accounting, Organizations and Society, 21(2/3), 139-173.

Ahrens, T., \& Dent, J.F. (1998). Accounting and organizations: realizing the richness of field research. Journal of Management Accounting Research, 10, 1-39.

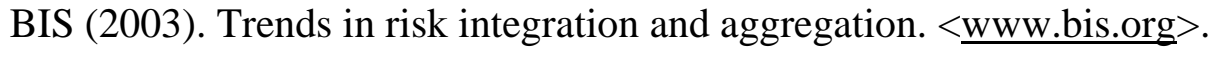

Barry, A., \& Slater, D. (2002). Introduction: the technological economy. Economy and Society, 31(2), 175193.

Bernstein, Peter L. (1996). Against The Gods: The Remarkable Story of Risk. New York, NY: John Wiley \& Sons. 
Bessis, J. (1998). Risk Management in Banking. New York, NY: John Wiley \& Sons.

Beunza, D.,\& Stark, D. (2004). Tools of the trade: the socio-technology of arbitrage in a Wall Street trading room. Industrial and Corporate Change, 13(2), 369-400.

Bookstaber, R. (2007). Where were the risk managers? $<$ http://blogs.wsj.com/economics/2007/10/16/bookstaber-asks-where-were-the-risk-managers/>.

Bruns, W.J., \& Kaplan, R.S.(1987). Field studies in management accounting. In W.J. Bruns, \& R.S. Kaplan (Eds.), Accounting and Management: Field Study Perspectives (pp.1-14). Cambridge, MA: Harvard Business School Press.

Boyle, D. (2001). The tyranny of numbers: Why counting can't make us happy. London: Harper-Collins.

Callon, M., \& Latour, B. (1981). Unscrewing the Big Leviathan: How Actors Macro-Structure Reality and How Sociologists Help Them Do So. In K. Knorr-Cetina, \& A.V. Cicouvel (Eds.), Advances in Social Theory and Methodology: Towards an Integration of Micro and Macro-Sociology (pp. 277303). Boston, MA: Routledge.

Callon, M., \& Law, J. (2005). On qualculation, agency, and otherness. Environment and Planning D: Society and Space, 23(5), $717-733$

Collins, H. M., \& Evans, R. J. (2002). The Third Wave of Science Studies: Studies of Expertise and Experience. Social Studies of Sciences, 32 (2), 235-96.

Dobs, K. (2008). Risk Chiefs: As the Bar Rises, So Does Demand. American Banker, 73 (21), 1-2.

Drzik, J., Nakada, P., \& Schuermann T. (2004). Risk capital measurement in financial institutions - part one. <www.Erisk.com>.

Economist Intelligence Unit (2005). Global Risk Briefing.London: Economist Intelligence Unit.

Field, P. (Ed.). (2003). Modern Risk Management - A History. London: Risk Books.

Geertz, C. (1973). Thick Description: Toward an Interpretive Theory of Culture. In C. Geertz (Ed.), The Interpretation of Cultures: Selected Essays (pp.3-30). New York, NY: Basic Books.

Gieryn, Thomas F. (1983). Boundary-work and the demarcation of science from non-science: strains and interests in professional ideologies of scientists. American Sociological Review, 48 (6), 781-795.

Hedberg, B., \& Jonsson, S. (1978). Designing semi-confusing information systems for organizations in changing environments. Accounting, Organizations and Society, 3(1), 47-64.

Hopwood, A.G. (1983). On trying to study accounting in the contexts in which it operates. Accounting, Organizations and Society, 8(2/3), 287-305. 
Hopwood, A.G. (1987). The archaeology of accounting systems. Accounting, Organizations and Society, 12(3), 207-234.

Hopwood, A.G., \& Miller, P. (Eds.). (1994). Accounting as Social and Institutional Practice. Cambridge: Cambridge University Press.

Jasanoff, S., (1990). The Fifth Branch: Science Advisors as Policymakers. Cambridge, MA: Harvard University Press.

Jorion, P. (1997). Value at Risk : The New Benchmark for Controlling Market Risks. Chicago, IL: Irwin Professional Publishing.

Kleindorfer, P.R. (2010). Reflections on Decision-making under Uncertainty. In: Diebold, F.X., Doherty, N.A. \& Herring, R.J., The Known, the Unknown and the Unknowable in Financial Risk Management. Princeton and Oxford: Princeton University Press.

Knight, F. H. (1921). Risk, Uncertainty and Profit. Mineola, NY: Dover Publications.

Lamont, M. \& Molnar, V. (2002). The study of boundaries in the social sciences. Annual Review of Sociology, Vol. 28, 167-195.

Lavoie, D. (1987). The accounting of interpretations and the interpretation of accounts: The communicative function of "the language of business". Accounting, Organizations and Society, 12 (6), 579-604.

MacKenzie, D. (2005). Opening the black boxes of global finance. Review of International Political Economy, 12(4), 555-576.

Mannheim, K. (1936). Ideology and Utopia. London: Routledge.

Marrison, C. (2002). The fundamentals of risk measurement. New York, NY: McGraw-Hill.

Mikes, A. (2007). Convictions, Conventions and the Operational Risk Maze-The Cases of Three Financial Services Institutions. International Journal of Risk Assessment and Management, 7(8), 1027-1056.

Mikes, A. (2008). Risk Management at Wellfleet Bank. Harvard Business School Case 109-071.

Mikes, A. (2009a). Risk Management and Calculative Cultures. Management Accounting Research, 20(1), 18-40.

Mikes, A. (2009b). Becoming the Lamp Bearer: The Emerging Roles of the Chief Risk Officer. Enterprise Risk Management: Today's Leading Research and Best Practices for Tomorrow's Executives. In J. Fraser, \& B. Simkins (Eds.). New York, NY: John Wiley \& Sons.

Mikes, A., Rose, C.S., \& Sesia, A. (2010). J.P. Morgan Private Bank: Risk Management during the Financial Crisis 2008-2009. Harvard Business School Case 311-003. 
Mikes, A., \& Townsend, D. (2007). Beyond compliance: The maturation of CROs and other senior risk executives. GARP Risk Review, 39, 12-18.

Miles, M. B., \& Huberman, A. M. (1994). Qualitative Data Analysis: An Expanded Sourcebook. London: Sage Publications, Chapter 7.

Millo, Y., \& MacKenzie, D. (2009). The usefulness of inaccurate models: Towards an understanding of the emergence of financial risk management. Accounting, Organizations and Society, 34(5), 638-653.

Mouritsen, J., Larsen, H.T., \& Bukh, P.N.D. (2001). Intellectual Capital and the 'Capable Firm': Narrating, Visualising and Numbering for Managing Knowledge. Accounting, Organizations and Society, 26(7/8), 735-762.

Parsons, T. (1967). Sociological Theory and Modern Society. New York, NY: Free Press.

Power, M.K. (2005). The Invention of Operational Risk. Review of International Political Economy, 12(4), 577-599.

Power, M.K. (2004a). Counting, control and calculation: Reflections on measuring and management. Human Relations, 57(6), 765-783.

Power, M.K. (2004b). The Risk Management of Everything. London: Demos.

Power, M.K. (2005). The Invention of Operational Risk. Review of International Political Economy, 12(4), 577-599.

Power, M.K. (2007). Organized Uncertainty - Designing a World of Risk Management. Oxford: Oxford University Press.

Power, M.K. (2009). The risk management of nothing. Accounting, Organizations and Society, 34 (6/7), 849-855.

PricewaterhouseCoopers (2007). Creating Value: Effective Risk Management in Financial Services. <http://www.pwc.com/gx/en/financial-services/briefing-programme/effective-risk-management-infinancial-services.jhtml>.

Sarfatti-Larson, M. (1979). The Rise of Professionalism. Berkley: Univ. Calif. Press.

Senior Supervisors Group (2008). Observations on Risk Management Practices during the Recent Market Turbulence.

<http://www.ny.frb.org/newsevents/news/banking/2008/SSG_Risk_Mgt_doc_final.pdf >.

Simons, R. (1991). Strategic orientation and top management attention to control systems. Strategic Management Journal, 12(1), 49-62.

Simons, R. (1999). How Risky Is Your Company? Harvard Business Review, 77(3), 85-94. 
Swieringa, R.J., \& Weick, K.E. (1987). Management accounting and action. Accounting, Organizations and Society, 12(3), 293-308.

Taleb, N.M. (2007). The Black Swan: The Impact of the Highly Improbable. New York, NY: Random House.

Treasury Committee (of the United Kingdom Parliament House of Commons). (2007a). Minutes of Evidence Taken before Treasury Committee, Tuesday 4 December 2007. $<$ http://www.publications.parliament.uk/pa/cm/cmtreasy.htm on 10 January 2008>.

Treasury Committee (of the United Kingdom Parliament House of Commons). (2007a). Minutes of Evidence Taken before Treasury Committee, Tuesday 16 October 2007. $<$ http://www.publications.parliament.uk/pa/cm200607/cmselect/cmtreasy/cmtreasy.htm on 10 January 2008>.

Yin, R.K. (1984). Case study research: Design and methods. Beverly Hills, CA: Sage Publications.

Vollmer, H. (2007). How to Do More With Numbers. Elementary Stakes, Framing, Keying, and the ThreeDimensional Character of Numerical Signs. Accounting, Organizations and Society, 32(6), 577600. 